\title{
Transparency in food supply chains: empirical results from German pig and dairy production
}

\author{
Mark Deimel, Mechthild Frentrup and Ludwig Theuvsen \\ Georg-August University Goettingen, Department of Agricultural Economics and Rural Development, Platz der Goettinger Sieben 5, \\ 37073 Goettingen, Germany; mdeimel@uni-goettingen.de
}

\begin{abstract}
Food supply chains have been faced with increasing requirements for transparency in recent years. However, evaluating the status quo of transparency of netchains entails measurement problems, since transparency is a multifaceted phenomenon as well as a latent variable. In this paper we present a measurement model that integrates various perspectives on transparency and, moreover, considers various measurement concepts. This model provides a theoretical basis for the empirical analysis of transparency in German pig and dairy production, which reveals interesting differences between the two sectors as perceived by farmers. The model and the empirical results deliver a more comprehensive understanding of the determinants and effects of various degrees of transparency in food supply chains.
\end{abstract}

Keywords: transparency, netchain performance, factor analysis, dairy, pork

\section{Introduction}

Compounded by a number of crises in the agribusiness sector and growing customer demand, transparency has gained much relevance in food supply chains in recent years. As a consequence, new legislation has been passed by the European Union to make production processes more transparent (for instance, Regulation (EC) 178/2002; Theuvsen and Hollmann-Hespos, 2007). Besides traceability, various research strands in supply chain management highlight various aspects of transparency, such as consumer trust due to improved access to information (Meuwissen $e t$ al., 2003), quality assurance (Engler et al., 2007), market orientation (Mohr and Nevin, 1990), and product and process innovations (Dyer and Singh, 1998). Hofstede (2003a) points out that, in today's complex and rapidly changing environments, effective information exchange is the key to improving value chain performance and competitiveness. It is a widely shared view that transparency and related concepts, such as trust, deserve more attention in firm management (Van Dijk et al., 2003; Hanf and Hanf, 2007; Fritz and Fischer, 2007).

In the literature there are various definitions of transparency based on a number of research perspectives. So far, most papers have discussed transparency only in a theoretical way without presenting measurement concepts or even empirical evidence. Therefore, the objective of this paper is to identify the determinants and effects of transparency and integrate them into a measurement model. This model provides a basis for a large-scale empirical study in German pork and dairy production whose results are also presented in this paper.

\section{Transparency}

Transparency is a multifaceted phenomenon that is referred to in a number of disciplines. In everyday understanding, transparency means clearness and lucidity and implies honesty and openness (Jensen, 2001; Hofstede et al., 2004). Sociologists relate transparency to the process of gaining information about the environment in order to prepare certain actions; they identify transparency as the main motivational factor in human behavior (Karg, 1990; Winterstein, 1996). Economists describe transparency as vital for market economies to function. Transparency from this perspective means a complete and detailed overview of all market conditions that is available to all market partners at the same time and that provides buyers and customers with information about products and prices (Krone, 2003). All in all, the transparency issue has developed into a general demand in respect of social systems and, with regard to agribusiness, the right to transparency is based on a number of legal norms in the food laws.

Against this background, most people associate transparency with systems or strategies for tracking and tracing food products. But transparency is more than just tracking and tracing (or history transparency; Hofstede, 2003b); it also includes elements like orientation, participation and communication. In this sense, Hofstede (2003a, 2003b) differentiates between operations transparency and strategy 
transparency. Operations transparency is the result of the coordination of business operations through, for instance, collaborative planning of daily activities, such as logistics. Strategy transparency includes reciprocal information flows on future-oriented perspectives (for instance, collaborative product innovation). Generally speaking, transparency 'is the extent to which all the netchain's stakeholders have a shared understanding of, and access to, the product-related information that they request, without loss, noise, delay and distortion' (Hofstede, 2003a, p. 18).

\section{Measuring transparency: a model}

Anecdotal evidence suggests that degrees of transparency vary remarkably between different supply chains. When trying to measure these differences, measurement problems arise because transparency is a latent variable that cannot be observed and measured directly. There are two approaches to specify latent constructs. In a reflective specification the construct is the cause of the indicators (observable variables). In contrast, in a formative specification the observable indicators cause the latent construct; in this case, it is necessary to enumerate all the variables that determine the latent construct (Jarvis et al., 2003).

Taking this distinction into account, the first step in developing a measurement model for transparency is to find its most important antecedents. Theuvsen (2003, 2004) identifies two dimensions, arguing that barriers to transparency arise due to structural and behavioral factors in supply chains. Structural determinants of transparency reflect supply chain, product and transaction characteristics, whereas behavioral determinants include cultural aspects and social embeddedness, transactors' behavior and the quality of business relationships between suppliers and customers.

An alternative method in evaluating transparency is measuring its observable effects. Due to recent food crises, product and process quality and safety have become paramount - alongside efficiency - (Babuchowski et al., 2005; Aramyan et al., 2006) and, thus, can be used as indicators of chain performance for measuring the effects of transparency. Another approach to measuring transparency is presented by Karg (1990) and Winterstein (1996). Starting from the sociological point of view, they interpret transparency from the perspective of information addressees and describe perceived transparency as the addressees' feeling or experience of being informed about relevant aspects.

Figure 1 presents the theoretical framework underlying the measurement of transparency. It is based on the formative and the reflective formation of the latent construct 'transparency'. Therefore, it integrates the main determinants of transparency, the effects of transparency on value chain performance and the perception of transparency by supply chain partners. These constructs will be outlined in greater detail below.

\section{Determinants of transparency}

\section{Supply chain characteristics}

Supply chains are characterized by a division of labor resulting in input-output relationships between different companies. Theuvsen (2003) identifies these input-output relationships - in organization theory they are called

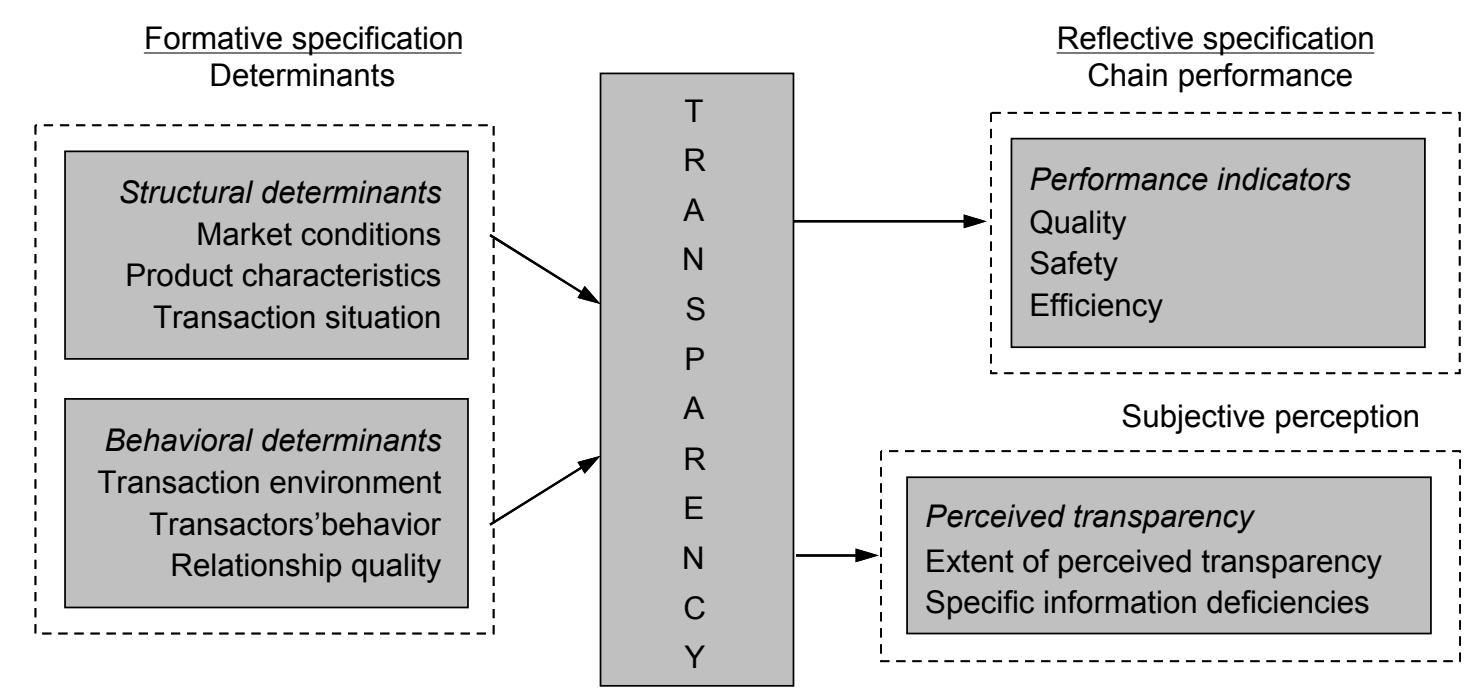

Figure 1. Theoretical framework: formative and reflective specification of transparency. 
interdependencies (for instance, Van de Ven et al., 1976) - as the main source of coordination problems in supply chains. Due to the fact that each interdependence represents a point where information is handed over between supply chain partners, a high number of process interdependencies - representing an intense division of labor - has a negative impact on information transfer and on transparency. The number of process interdependencies in a supply chain depends on the following supply chain characteristics (Theuvsen, 2004):

- The length of the supply chain, which is influenced by the degree of specialization and the degree of vertical (dis)integration in the supply chain.

- The number of potential transaction partners, i.e. the number of suppliers and customers each company in the food chain can choose between, and the number of actual transaction partners a firm has.

- The frequency of transactions, which describes how often transaction partners have exchange relationships (Williamson, 1985), and the extent of transactions, i.e. the quantities delivered between supply chain partners.

- The geographical distance, which influences the complexity of coordination and the extent of information transfer problems that require the use of richer media (for instance, personal contact in face-to-face conversations) (Daft and Lengel, 1986).

\section{Product characteristics}

The transfer of information through supply chains depends very much on product characteristics. Transparency problems arise from the fact that agricultural products are mostly bulk products without obvious specific characteristics (for instance, milk or wheat). This makes products highly exchangeable and implies that the same product can be supplied by a large number of different participants in the chain. Furthermore, food products are often characterized by credence attributes that cannot be controlled or can only be controlled at high cost by customers and consumers (Nelson, 1970).

\section{Transaction characteristics}

Other key drivers of transparency are the characteristics of a transaction (Boerner and Macher, 2002; Sherer, 2003), which include a transaction's complexity and uncertainty, transaction-specific investments, the governance structure, the structural embeddedness of transactions and the explicitness of information that needs to be shared.

The influence of complexity and uncertainty on transaction costs (Williamson, 1985) and transaction-related information exchange behavior (Brand, 1990) is widely discussed. Sociologists and psychologists support the assumption that complexity and uncertainty have a positive impact on transparency because in a complex and uncertain environment the transaction partners need more information to take certain decisions. This means that the motivation to search and collect information and to overcome potential information transfer problems might be higher as well as transparency itself (Winterstein, 1996).

Assuming a power-balanced relationship between transaction partners, transaction-specific investments impact transparency in a positive way because they result in a fundamental transformation that creates (mutual) dependency between transaction partners (Williamson, 1985). Dependency increases the motivation to know as much as possible about the supply chain partner and the transaction itself and, thus, transparency may be influenced positively.

According to Van Dijk et al. (2003), the governance structure determines a framework for information exchange behavior. Less cooperative governance structures characterized by opportunistic behavior and power asymmetries, for instance, lead to information asymmetries and impact transparency in a negative way. Therefore, supply chain collaboration is strongly demanded in order to improve transparency (Horvath, 2001; Matopoulos et al., 2007).

Yao and McEvily (2001) point out that a firm's position in a network strongly determines its access to information circulating among network members. Therefore, the structural embeddedness of a transaction is essential for solving the supply chain information problem (Sporleder and Goldsmith, 2002). Structural embeddedness can be defined as the extent to which a 'dyad's mutual contacts are connected to one another' (Granovetter, 1992, p. 35). In an embedded transaction characterized by a dense network, control mechanisms and governance work, power asymmetries presumably decrease and transparency increases.

The characteristics of the information that needs to be shared also impact the process of information exchange. Explicit information is easier to communicate than implicit information; it is easier to express and needs less additional interpretation by the transaction partners who receive it (Nonaka and Takeuchi, 1995). In this way, the explicitness of information has a positive effect on transparency. Furthermore, high strategic relevance of the information enhances the partners' motivation to receive it (Van Dijk et al., 2003).

Culture and social embeddedness

The cultural background determines the so-called 'hidden rules of the game' as well as the 'declared rules' between business partners (Hofstede et al., 2004). The 'social fabric' 
(expressed by masculinity/femininity, individualism/ collectivism, uncertainty avoidance, power distance and long-term/short-term orientation) is often more important for a successful business relationship than technology. Van Dijk et al. (2003) identify cultural (and physical) closeness as important factors that influence transparency in a positive way because a 'shared understanding of information' (Hofstede, 2003a) as a precondition for transparency is more likely to occur if humans share the same language and the same horizon of experience.

Social embeddedness represents a behavioral safeguard against opportunistic behavior and information asymmetries and complements structural safeguards, such as governance structure and structural embeddedness. Van Dijk et al. (2003) highlight trust between business partners as a governance mechanism that has positive effects on information exchange behavior and on transparency. Dyer and Chu (2000) argue that trust between transaction partners emerges through the embeddedness of the transaction in a structure of (formal or informal) standards and norms, which is influenced by the cultural background of the transaction partners. A network of social contacts is vital for trust-building (and for transparency) because it includes more partners to communicate with in order to get more information about the partner. In addition, a strong social network provides a greater choice of potential transaction partners; as a possible consequence, it decreases power asymmetries and opportunistic behavior and, thus, increases transparency.

\section{Transactors' behavior}

Abuse of power limits transparency. In power-asymmetric relationships, transparency is often negatively imposed by the dominant partner who controls the information flow and communication is not based on a mutual exchange of shared information. On the other hand, the impact of power asymmetries on transparency might become a positive one if the dominant partner does not exploit his or her position but acts as a supply chain leader (Koester, 2003).

In addition, the frequency and quality of communication between business partners strongly depend on their willingness to communicate in general. High willingness to communicate in a cooperative, reciprocal manner favors an intensive and mutual information exchange, impacting transparency in a positive way.

\section{Relationship quality}

Relationship quality is 'the overall assessment of the strength of a business relationship' (Schulze et al., 2006, p. 57) and affects the willingness of transaction partners to cooperate more closely with each other and determines their information exchange behavior. The higher the relationship quality the higher the transparency of supply chains. With regard to relationships in the agrifood sector, Gerlach et al. (2004) suggest a measurement scale that conceptualizes relationship quality as a construct composed of three different but interrelated elements: satisfaction, trust and commitment.

Satisfaction reflects comprehensive experience with a business partner and is a necessary but not sufficient condition for an ongoing business relationship (Van Weele, 2002). With regard to the pork industry, Schulze and Spiller (2006) identify price satisfaction, perceived management competence, enterprise performance, image/reputation and relationship duration as important elements of supply chain partners' satisfaction with their business relationships.

Trust is 'a psychological state comprising the intention to accept vulnerability based upon positive expectations of the intentions or behavior of another' (Rousseau et al., 1998, p. 395). Vulnerability implies the risk of being disappointed or violated as a basic trait of trust (Coleman, 1990; Dyer and Chu, 2000). All in all, benevolence/fairness, integrity, reliability/credibility, conflict management, fulfillment of promises and reputation are the most important trustbuilding factors.

Commitment describes the belief of a business partner that the relationship with another partner is important enough to maintain even if problems occur (Schulze et al., 2006). The main aspects of commitment in a business relationship are the reliability of the partner, the continuity of the relationship and the long-term orientation of the partner. A higher commitment results in a lower willingness to change the current business partner.

\section{Effects of transparency: chain performance and subjective perceptions}

An alternative approach to measure transparency is to address its outcomes. In the literature transparency is identified as valuable for the creation of effective and profitable business networks (Van Dijk et al., 2003; Hofstede et al., 2004). Thus, generally speaking, the performance of supply chains represents the main target of transparency. Aramyan et al. (2006) present a conceptual framework for measuring agrifood supply chain performance, which includes efficiency, flexibility and responsiveness. The authors point out that each category needs to be analyzed with regard to quality, time and costs. A similar approach is presented by Babuchowski et al. (2005), who argue that agribusiness supply chains need to focus on quality, safety and efficiency. Empirical research can try to measure the effects of transparency on the various dimensions of supply chain performance. 
A different approach rooted in sociology emphasizes that transparency enables individuals to orientate themselves in their environments in order to reach their subjective targets (Winterstein, 1996). Transparency might be perceived differently between individuals because its perception is mainly determined by the limited ability of individuals to collect, process and transfer information as well as by subjective feelings and experiences in the past. Following these ideas, Karg (1990) describes perceived transparency as the feeling of being informed about something and defines it as the availability of relevant information as experienced by the individual that makes processes subjectively distinct and clear.

Based on Karg's approach, a large number of empirical studies have been conducted in order to test the theoretical concept and its relevance for practical management in different business environments (Winterstein, 1996). Generally, the measurement scale for perceived transparency comprises two elements: First, the extent of perceived transparency is measured, which is determined by the general impression of being informed, the timeliness of being informed, the general overview of the organization and the perceived amount of shared information. Second, specific information deficits are identified in order to recommend strategies for improving perceived transparency (Franke and Winterstein, 1996).

In our study we focused on the respondents' perception of chain performance and transparency (reflective specification) in addition to evaluating the determinants of transparency (formative specification).

\section{Methodology}

The theoretical framework outlined above guided a largescale empirical study in German pork and dairy production. Due to the fact that pork and dairy production are the two most important food supply chains in German agribusiness, this paper focuses on transparency as experienced by dairy and pig farmers. Moreover, a varying intensity of political market regulations (e.g. milk quota) and different supply chain organizations suggest interesting differences between both sectors, particularly with regard to transparency. Between May and August 2007, 107 dairy farmers and 104 pig farmers were surveyed in extensive face-to-face, questionnaire-based interviews. The above-average number of animals per farm, the high percentage of income coming from dairy or pig production, the high percentage of farmers intending to enlarge their production capacities, the prevalence of farmers with advanced agrarian education and the high perceived farm success indicate that mainly future-oriented farmers were interviewed (see Table 1). The questionnaire was divided into three main sections. In the first section, the respondents were asked several questions about themselves and their farms in order to characterize the sample in general. The second section concentrated on statements about the determinants of transparency in dairy and pork value chains to be answered with regard to the respondent's own farm and the farm's main supply chain partner. The third section focused on the farmers' subjective perceptions of transparency in their specific businesses. The questionnaire mostly consisted of seven-point Likert scales from ' -3 : strongly disagree' to ' +3 : strongly agree'. Some rating scales ranged from 0 to 100 and a few ordinal scales were also included. In order to guarantee comparability between both supply chains, all questions were identical for dairy and pig farmers except some sector-specific wordings.

In a pre-test, respondents revealed no difficulties with the questionnaire. For data analysis, SPSS 12.0 for Windows was used. Data analyses included univariate analyses and factor analyses to identify the main determinants of transparency and transparency perception of food chain members. Finally, transparency profiles of German pork and dairy production were developed.

\section{Table 1. Sample characteristics.}

Sample characteristics

Sample size

Average number of cows/pigs per farm

Percentage of income coming from dairy/pork production

Percentage of farmers planning to enlarge production capacities

Percentage of farmers with an advanced agrarian education

Average estimation of business success on scale from 0 to $100 \%$
Dairy farmers

Pig farmers

107

104

61

1,704

$64.9 \%$

$54.7 \%$

$56.2 \%$

$63.4 \%$

$81.9 \%$

$70.0 \%$

$63.6 \%$
$69.5 \%$ 


\section{Results and discussion}

As mentioned above, questions focusing on the determinants of transparency were to be answered with regard to the respondent's main supply chain partner (dairy or slaughterhouse). It turned out that the 107 dairy farmers deliver their milk to 14 different dairies, among which Nordmilch (43.4\%), Humana Milchunion (19.8\%), Molkerei Ammerland (12.3\%), Campina Germany (8.5\%) and Milchwerke Gebr. Bermes (7.5\%) have major market shares. The 104 pork farmers supply their pigs to 36 different big and small slaughterhouses (18.7\% Vion/NFZ, 15.4\% D\&S Fleisch, 9.9\% Böseler Goldschmaus, 8.8\% Brand Qualitätsfleisch, 7.7\% Toennies Fleischwerk/Weidemark Fleischwaren, 6.6\% Steinemann, 3.3\% Westfleisch).

Most of the dairy farmers (93.5\%) deliver their milk to only one dairy company. The picture is more mixed in pork production, where pig farmers deal with one $(20.2 \%)$, two (27.9\%), three $(21.2 \%)$, four $(14.4 \%)$ or even five $(10.6 \%)$ slaughterhouses. The number of farmers' actual transaction partners varies from one to three in the dairy sector and one to fifteen in pork production, whereas the number of potential transaction partners reaches a maximum of eight in the dairy and forty in the pork business.

Due to certain characteristics of milk (for instance, limited shelf-life) and dairy production (such as constant production), most dairy farmers $(92.5 \%)$ deliver their milk every second day to their dairy company's processing plant. The average amount of milk delivered per transaction is $2,911 \mathrm{~kg}$, and $53.8 \%$ of the respondents estimate that the distance to the processing unit is approximately $50 \mathrm{~km}$. The pork farmers supply their pigs less frequently; $35 \%$ of the pork farmers supply once a week, and another 35\% once every second week. They supply smaller quantities per transaction (on average 125 animals), and, in 49.5\% of the cases surveyed, the slaughterhouse is located within a distance of approximately $20 \mathrm{~km}$. Thus, with regard to supply chain characteristics, which are considered one of the key drivers of transparency, the situation differs remarkably between the dairy and pork sectors. In order to provide a more detailed picture of transparency in German pork and dairy production, Figure 2 (determinants of transparency) and Figure 3 (perceived transparency) present results for selected variables.

It is striking that not only the supply chain characteristics but also transaction characteristics are very different between both agribusiness subsectors (Figure 2). In general, the governance structures used to coordinate and control transactions are more contract-based and more focused on the initiation of long-term partnerships in the dairy than in the pork sector. Pig farmers act more spontaneously and change transaction partners more often. Whereas pig farmers have to make decisions being confronted with risky market conditions, dairy farmers face risky political conditions. Although the number of transaction-specific investments is not clearly distinct between the two sectors, dairy farmers need to invest more in their farms to fulfill their transaction partner's specific requirements, and they more often have to be shareholders in their supply chain partner before being allowed to deliver their products. This result reflects the stronger role of cooperatives in the German dairy industry compared to the pork sector, which is characterized by a majority of privately owned slaughterhouses. It also corresponds with the initial impression of higher transparency in the dairy sector. The farmers surveyed indicate that the clearness and explicitness of information, another important driver of transparency, is higher in the dairy sector. With regard to the cultural background, pig and dairy farmers both agree that their transaction partners do not play games with hidden rules. Nevertheless, at the same time they are equally convinced that dairies and slaughterhouses on the one hand and farmers on the other hand do not think in identical structures.

With regard to the transactors' behavior, pig and dairy farmers both complain of deficits in the mutuality and regularity of communication between supply chain partners; these deficits are perceived somewhat more strongly in the pork sector. The respondents in both groups characterize their customers as the dominant partners in the business relationships, and dairy farmers even more than pig farmers say that they lack opportunities to influence prices and conditions.

There are clear differences between both sectors with regard to relationship quality - i.e., satisfaction, trust and commitment. In contrast to pig farmers, dairy farmers trust their dairy company and are convinced that their partner acts fairly and honestly. Nevertheless, dairy farmers do not think that the dairy they deliver to is the best one in the business and their price satisfaction is low. Since pig farmers perceive the customer they deliver to as the best available alternative, they are more willing to recommend their preferred slaughterhouse to other farmers. Furthermore, they are satisfied with the collaboration with the slaughterhouse and with the prices paid in recent years. Nevertheless, pig farmers do not feel committed to their slaughterhouses and would not sign long-term contracts with them. Again, the situation in the dairy sector looks completely different.

Perceived transparency differs between the two sectors with regard to the general impression of being informed and with regard to specific information areas (Figure 3). Dairy farmers feel better informed about the value chain in general and the future perspectives of their processors than do pig farmers. Farmers in both sectors are equally well-informed about their own farm (production costs, profits and losses, etc.) but pig farmers lack information about their slaughterhouses' future 


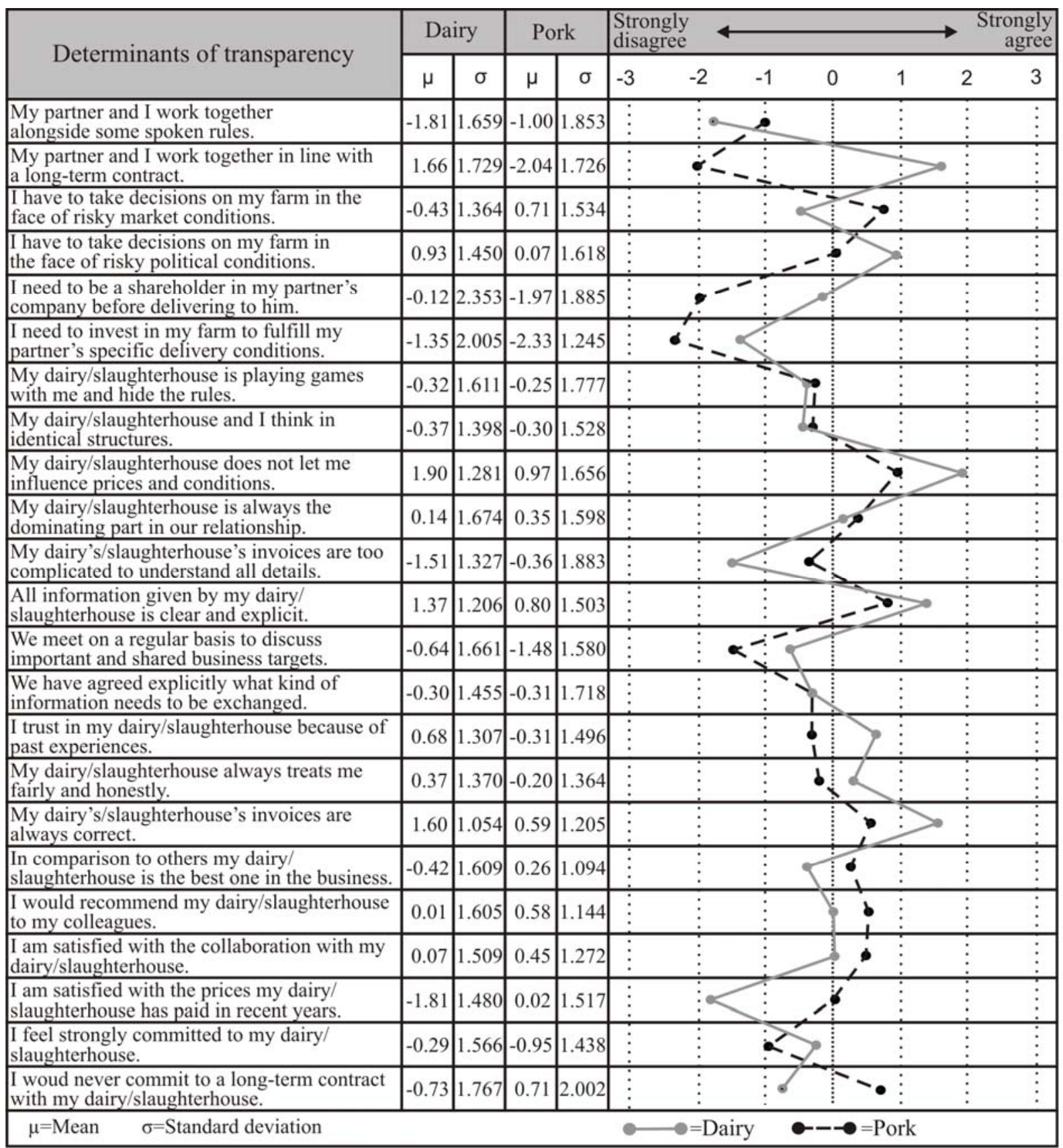

Figure 2. Selected determinants of transparency.

perspectives and alternative market partners. All in all, the subjective transparency as perceived by dairy farmers seems to be higher than that of pig farmers.

In order to identify the main determinants and indicators of transparency in dairy and pork value chains, a factor analysis (principal component analysis) was conducted. First, the correlation values between all variables were analyzed, and variables with high correlation values formed an initial structure of higher-order constructs, which were then checked using a factor analysis (Figure 4). On the formative side of the model, the variables describe structural aspects, such as supply chain characteristics and characteristics of the transaction process, as well as behavioral aspects, such as transactors' behavior and relationship quality. In contrast to our theoretical model, the empirical data do not reflect a distinction between the social and cultural 


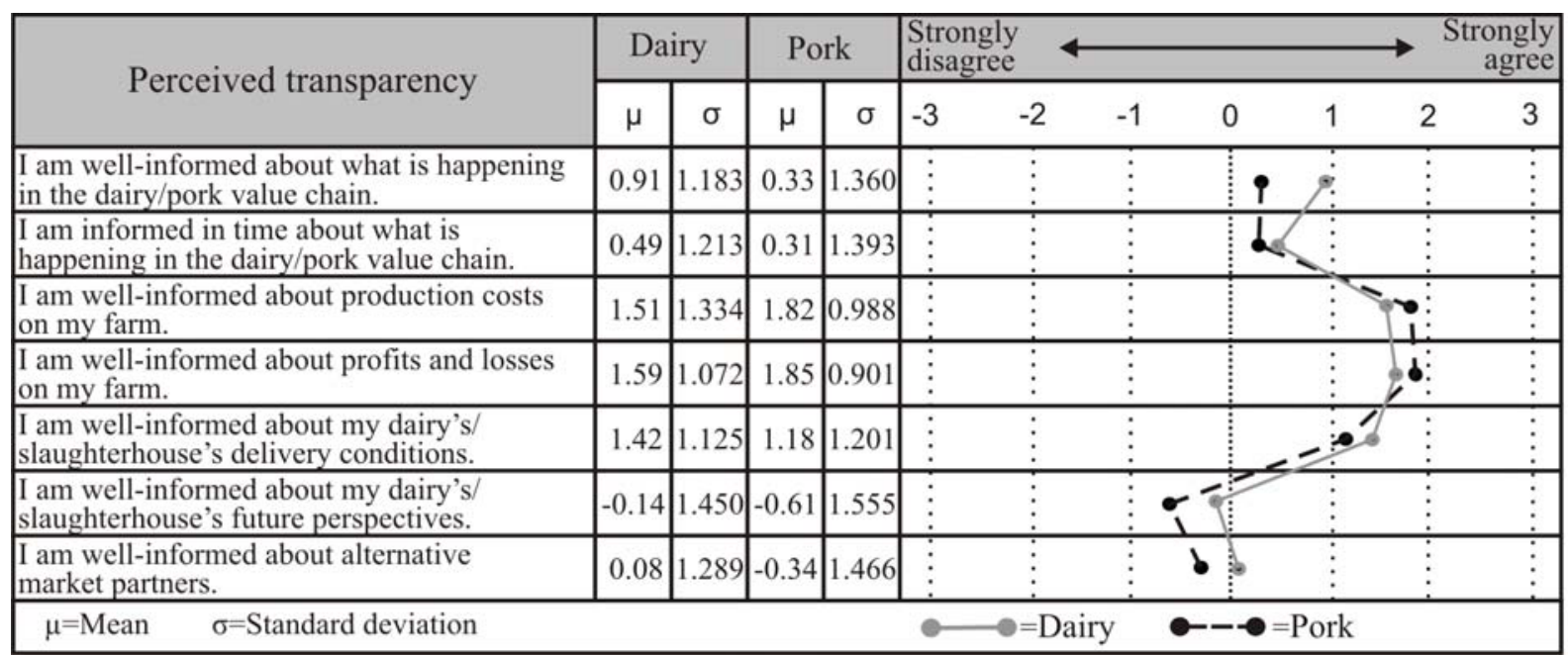

Figure 3. Perceived transparency.

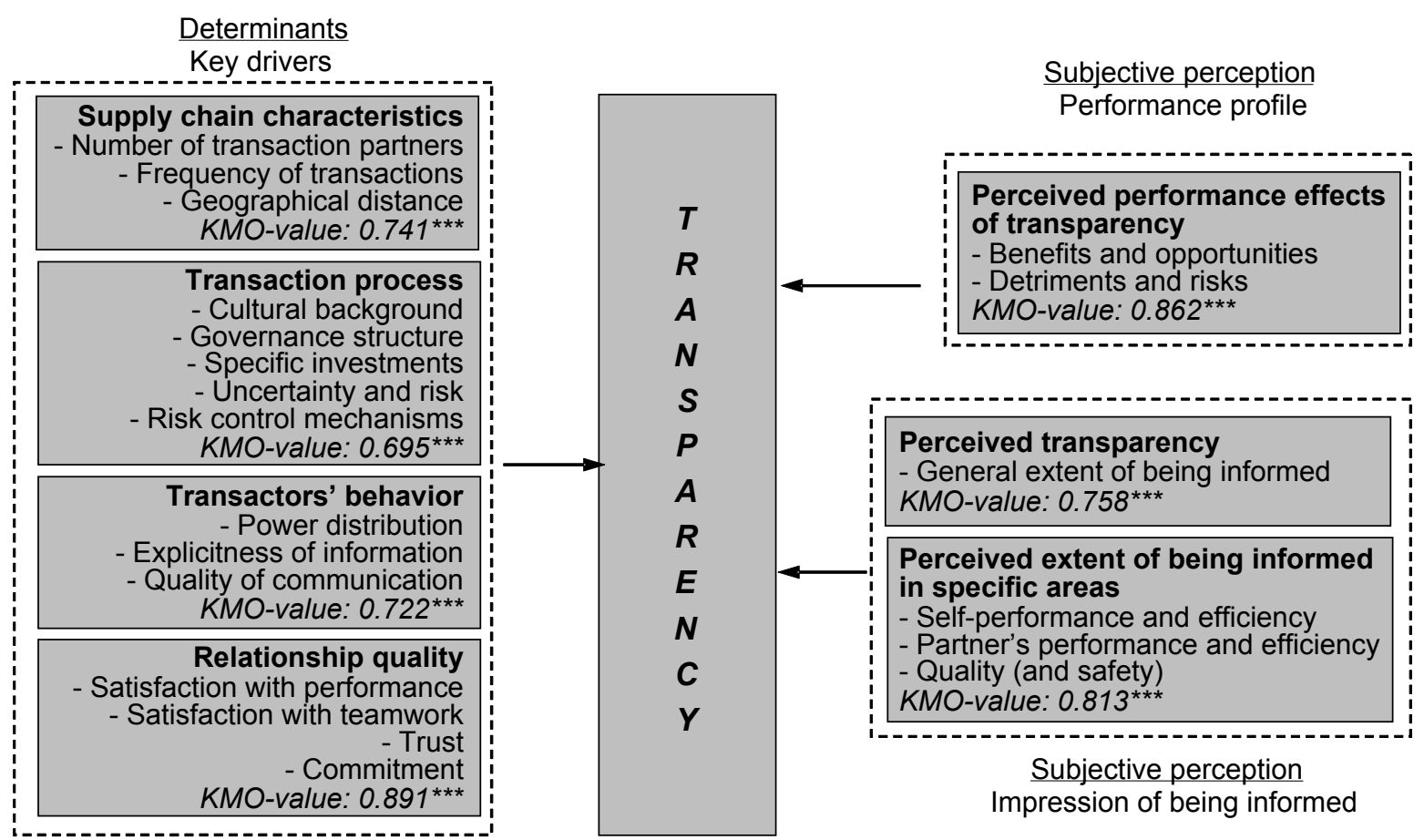

Figure 4. Factor analysis: the empirical framework of transparency.

embeddedness of the transactions and the transaction process, nor do they allow identification of product characteristics as a determinant of transparency. For this reason, the empirically based model is somewhat different from the determinants of transparency summarized in the theoretical framework outlined above. On the reflective side of the model, the variables surveyed can be summarized as perceived performance of transparency, perceived transparency in general and perceived extent of being informed in specific areas. Next, a single factor analysis was carried out for each of the seven dimensions introduced above in order to determine the distinct structure behind the data: $\mathrm{KMO}$ values of 0.741 (supply chain characteristics), 0.695 (transaction process), 0.722 (transactors' behavior), 0.891 (relationship quality), 0.862 (perceived performance effects of transparency), 0.758 (perceived transparency) and 0.813 (perceived 
Table 2. Key figures of selected factors and variables.

\begin{tabular}{|c|c|c|}
\hline Description & $\mathrm{a}$ & $\alpha$ \\
\hline \multicolumn{3}{|l|}{ Cultural background } \\
\hline Playing games with hidden rules & 0.924 & \\
\hline Speaking different languages & 0.910 & 0.887 \\
\hline Thinking in identical structures & 0.826 & \\
\hline \multicolumn{3}{|l|}{ Coordination and control } \\
\hline Spontaneous choice between partners & 0.805 & \\
\hline Long-term contract with the partner & 0.780 & 0.680 \\
\hline Support by institutions representing farmers' interest & 0.686 & \\
\hline Existence of specific governmental laws and orders & 0.501 & \\
\hline \multicolumn{3}{|l|}{ Satisfaction with performance } \\
\hline Management competence of the partner & 0.837 & \\
\hline Belief that the partner is the best in the business & 0.824 & \\
\hline Satisfaction with the partner in comparison to others & 0.820 & 0.897 \\
\hline Conviction of the partner's long-term success & 0.818 & \\
\hline Recommendation to colleagues & 0.791 & \\
\hline Satisfaction with prices paid in recent years & 0.639 & \\
\hline \multicolumn{3}{|l|}{ Trust } \\
\hline Correctness of invoices & 0.735 & \\
\hline Punctuality of payment & 0.630 & \\
\hline Trust based on past experience & 0.628 & \\
\hline No distrust & 0.574 & 0.824 \\
\hline Fairness and honesty & 0.523 & \\
\hline Credibility of the information & 0.513 & \\
\hline Reliability of the partner & 0.477 & \\
\hline \multicolumn{3}{|l|}{ General extent of being informed } \\
\hline General impression of being informed & 0.856 & \\
\hline Timeliness of being informed & 0.834 & 0.785 \\
\hline General survey of the business & 0.830 & \\
\hline Perceived amount of imparted information & 0.589 & \\
\hline \multicolumn{3}{|l|}{ Self performance and efficiency } \\
\hline Being informed about laws and order & 0.823 & \\
\hline Being informed about management demands & 0.810 & \\
\hline Being informed about the farmers' own production profits & 0.767 & 0.869 \\
\hline Being informed about the farmers' own production costs & 0.760 & \\
\hline Being informed about production structures & 0.749 & \\
\hline Being informed about partner's conditions & 0.576 & \\
\hline \multicolumn{3}{|l|}{ Partner's performance and efficiency } \\
\hline Being informed about the partner's business results & 0.897 & \\
\hline Being informed about the partner's future perspectives & 0.890 & 0.793 \\
\hline Being informed about alternative partners & 0.684 & \\
\hline
\end{tabular}

$\mathrm{a}=$ Factor loading; $\alpha=$ Cronbach's alpha.

extent of being informed in specific areas) were obtained and Cronbach's alpha values - selected factor loadings for selected items are presented in Table 2 - indicate medium to high reliabilities of the model's improved scales.
Due to the multidimensional character of the latent construct including determinants and perceptions of chain performance and transparency, collinearity may turn out to be a problem that needs some additional attention. Therefore, 
all generated factors were checked by additional analyses of correlations, whose results indicate non-mentionable multicollinearity. Finally, it can be observed that the determinants and outcomes of transparency are represented by different numbers of factors (see Figure 4): Supply chain characteristics is represented by three factors (number of transaction partners, frequency of transactions and geographical distance), transaction process by five factors (cultural background, governance structure, specific investments, uncertainty and risk, and risk control mechanisms). Transactors' behavior depends on three factors (power distribution, explicitness of information and quality of communication) and relationship quality on four factors (satisfaction with performance, satisfaction with teamwork, trust and commitment). Perceived performance effects of transparency reflects two factors (benefits/ opportunities and detriments/risks), perceived transparency one factor (general extent of being informed), and perceived extent of being informed in specific areas three factors (selfperformance and efficiency, partner's performance and efficiency, and quality and safety).

In addition to reducing data to central structures and dimensions, the factor analysis provides methods to generate concrete factor scores which represent each respondent's evaluation of each factor and can be used in further analyses. Using principal component analysis, these factor scores were calculated on the basis of a specific coefficient matrix (items $\mathrm{x}$ factors) that takes into account the relevance of a respective item to a factor as well as the different numbers of items representing one factor. Each respondent's factor scores for each single factor were obtained by multiplying the coefficients by this respondent's answers to each item and summing up products factor-wise (for instance, summing up products for the seven items representing the factor trust in Table 2).

Figure 5 visualises the transparency profiles of the German pork and dairy chains. The transparency profiles in the spider web graphic display the mean values of all respondents' factor scores differentiated by dairy and pig producers $(0.5$ for low number of transaction partners, for instance, represents the mean value of 101 dairy farmers' factor scores). Since all factor scores represent standardised values, it is possible to compare various value chains with regard to different factors. The results can be considered quantitative assessments of transparency as experienced by the farmers interviewed. In line with the initial impression stemming from univariate analyses of empirical data as well as anecdotal evidence, the transparency profiles of the dairy and the pork chains are quite different and, all in all, transparency is somewhat higher in the dairy than in the pork business. Compared to pork production, transparency in the dairy chain is positively influenced by a lower number of transaction partners and a tendency toward a longer-term governance structure in transactions due to more specific investments. Furthermore, the explicitness and clearness of information exchanged and the levels of trust and commitment are higher in the dairy sector. On the other hand, the pork chain reveals transparency advantages over the dairy chain due to higher satisfaction with supply chain partners' performance, a more balanced distribution of power between the partners, and a lower frequency of transactions.

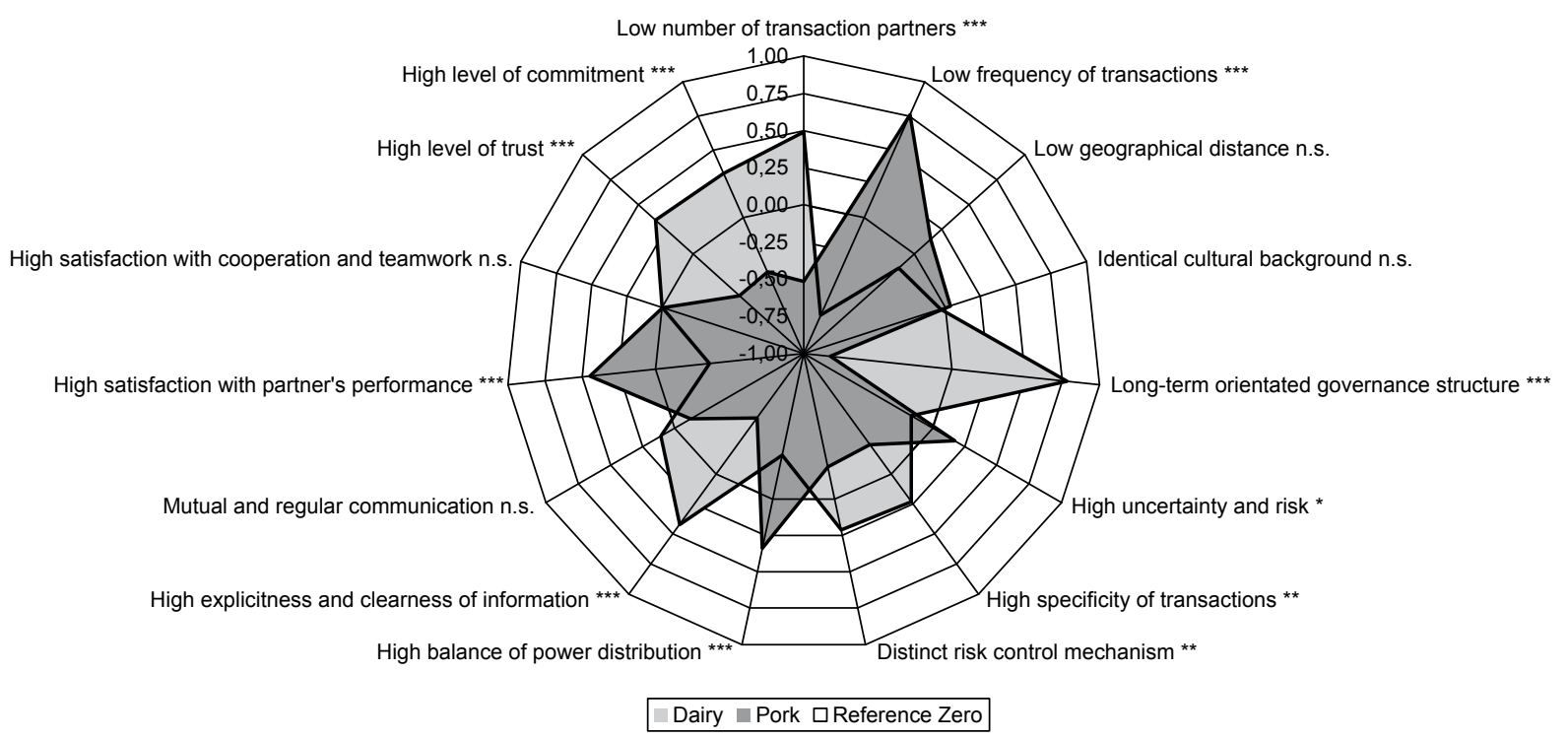

Figure 5. Transparency profiles of the dairy and pork chains (n.s.: Difference between dairy and pork chains are not significant. $*, * *, * * *$ : Differences between dairy and pork chains are significant to the $0.05,0.01$, or 0.001 level, respectively). 


\section{Conclusions and implications}

The empirical results of the study allow us to identify and evaluate the main drivers of transparency in German pork and dairy production. Anecdotal evidence, for instance, a high number of food safety incidents stemming from fraudulent behavior and a lack of consumer trust, suggests that the meat industry is one of the least transparent agrifood chains and that other chains have an advantage over the meat chain with regard to transparency. All in all, the empirical results reflect this everyday impression. Furthermore, we were able to empirically identify differences between the pork and dairy chains as well as advantages of the dairy chain over the pork chain with regard to transparency. The empirical results have interesting theoretical and managerial implications. From a theoretical perspective, the improved model of transparency, which reflects the integration of multidisciplinary perspectives on transparency into a single framework, provides a more comprehensive understanding of the determinants and effects of transparency in agrifood chains and networks. From a managerial perspective, the proposed transparency profiles enable researchers and business management to evaluate the actual degree of transparency of food supply chains, identify strengths and weaknesses of specific chains and identify strategies and actions necessary for improving transparency. All in all, the model can be considered a first step towards a contingent valuation of transparency in agrifood chains.

Further empirical research faces severe problems that need to be solved. Current writing on transparency in supply chains often reveals contradictory opinions, for instance, on the relationship between trust and transparency (Frentrup and Theuvsen, 2006). Therefore, some of the hypotheses underlying the model and the transparency profiles might be disputed by some authors since some of the hypotheses currently find mixed empirical support. Furthermore, it might be necessary to include more contingency factors that take into account factors such as differences between various agrifood subsectors or different countries with diverse cultural backgrounds. Therefore, we consider our measurement model a starting point and concede that it may need considerable refinement based on future conceptual and empirical research.

Future research should also more thoroughly address the model's applicability in practical business management. In day-to-day business, managers need tools that are easily applicable and provide clear managerial implications without requiring prior in-depth statistical analyses. Factor analyses and other multivariate analyses may lead to a more simplified model that improves the applicability of the model for agribusiness management.

\section{References}

Aramyan, L., C.J.M. Ondersteijn, O. van Kooten and A. Oude Lansink, 2006. Performance indicators in agri-food production chains. In: C.J.M. Ondersteijn, J.H.M. Wijnands, R.B.M. Huirne and O. van Kooten (Eds.), Quantifying the agri-food supply chain. Dordrecht: Springer, 47-64.

Babuchowski, A., F. Beekmans, J. Castenmiller, R. Fenwick, J. Haber, T. Hogg, D. Israelachwili, B. Kettlitz, J. Kohnke, K. Lienemann, D. Majou, B. Petersen, G. Schiefer and F. Tomás-Barberán. 2005. European technology platform on food for life: The vision for 2020 and beyond. Brussels: Conféderation des industries agroalimentaires de l'UE, July 2005.

Boerner, C.S. and J.T. Macher, 2002. Transaction cost economics: An assessment of empirical research in the social sciences. Working paper, Georgetown University.

Brand, D., 1990. Der Transaktionskostenansatz in der betriebswirtschaftlichen Organisationslehre. Frankfurt a. Main: Peter Lang.

Coleman, J.S., 1990. Foundations of social theory. Cambridge, MA: Belknap Press.

Daft, R.L. and R.H. Lengel, 1986. Organizational information requirements, media richness and structural design. Management Science, 32, 554-571.

Dyer, J.H. and Chu, W., 2000. The determinants of trust in supplierautomaker relationships in the U.S., Japan, and Korea. Journal of International Business Studies, 31: 259-285.

Dyer, J.H., and H. Singh, 1998. The relational view: Cooperative strategy and sources of interorganizational competitive advantage. Academy of Management Review, 23: 660-679.

Engler, A., G. Henry, D.H. Iglesias, A.F. Alves, G. Gutièrrez and E. Salay, 2007. Actor organization for QAS along agro supply chains: The case of mycotoxins reduction in Southern Cone grains. In: L. Theuvsen, A. Spiller, M. Peupert, G. Jahn (Eds.), Quality management in food chains. Wageningen: Wageningen Academic Publishers, pp. 475-488.

Franke, J. and H. Winterstein, 1996. Arbeitsbezogenes Transparenzerleben - Ein zentrales Element der Organisationsdiagnose. Munich and Mering: Hampp.

Frentrup, M. and L. Theuvsen, 2006. Transparency in supply chains: Is trust a limiting factor? In: M. Fritz, U. Rickert and G. Schiefer (Eds.): Trust and risk in business networks, Bonn: ILB-Press, pp. 65-74.

Fritz, M. and C. Fischer, 2007. The role of trust in European food chains: Theory and empirical findings. International Food and Agribusiness Management Review, 10: 141-163.

Gerlach, S., B. Köhler, A. Spiller and C. Wocken, 2004. Supplier Relationship Management im Agribusiness: Ein Konzept zur Messung der Geschäftsbeziehungsqualität. Discussion paper, University of Goettingen. 
Granovetter, M.S., 1992. Economic action and social structure. The problem of embeddedness. In: M.S. Granovetter and R. Swedberg (Eds.): The sociology of economic life. Boulder, Colorado: Westview Press, pp. 53-81.

Hanf, J. and C.-H. Hanf, 2007. Does food quality create a competitive advantage? In: L. Theuvsen, A. Spiller, M. Peupert, G. Jahn (Eds.), Quality management in food chains. Wageningen: Wageningen Academic Publishers, pp. 489-499.

Hofstede, G.J., 2003a. Transparency in netchains. In: Z. Harnos, M. Herdon and T. B. Wiwczaroski (editors), Information technology for a better agri-food sector, environment and rural living. Proceedings EFITA 2003 Conference. Debrecen University, Hungary, pp. 17-29.

Hofstede, G.J., 2003b. Trust and transparency in supply netchains: A contradiction? Paper presented at $8^{\text {th }}$ AIM Conference, Grenoble, May 2003.

Hofstede, G.J., H. Schepers, L. Spaans-Dijkstra, J. Trienekens and A. Beulens, 2004. Hide or confide? The dilemma of transparency. Reed Business Information BV.

Horvath, L., 2001. Collaboration: The key to value creation in supply chain management. Supply Chain Management, 6: 205-207.

Jarvis, C.B., S.B. Mackenzie and P.M. Podsakoff, 2003. A critical review of construct indicators and measurement model misspecification in marketing and consumer research. Journal of Consumer Research, 30: 199-218.

Jensen, H., 2001. Optimal degrees of transparency in monetary policymaking. Discussion paper 04/01. Economic Research Center of the Deutsche Bundesbank. Frankfurt a. Main.

Karg, K.R., 1990. Transparenz in Organisationen aus der Sicht ihrer Mitglieder. Ph.D. thesis, University of Erlangen-Nuremberg.

Koester, O., 2003. Trust development in power-asymmetric relationships. St. Gallen: Verlag für Wissenschaft und Forschung.

Krone, P., 2003. Horizontale Markttransparenz im Zeitalter einer Informationsgesellschaft: Eine kartellrechtliche Analyse unter besonderer Berücksichtigung der Marktmechanismen des elektronischen Handels. Hamburg: Kovac.

Matopoulos, A., M. Vlachopoulou and V. Manthou, 2007. A conceptual framework for supply chain collaboration: Empirical evidence from the agri-food industry. Supply Chain Management, 12: 177-186.

Meuwissen, M.P.M., A.G.J. Velthuis, H. Hogeveen and R.B.M. Huirne, 2003. Traceability and certification in meat supply chains. Journal of Agribusiness, 21: 167-181.

Mohr, J. and J.R. Nevin, 1990. Communication strategies in marketing channels: A theoretical perspective. Journal of Marketing, 54: 36-51.

Nelson, P., 1970. Information and consumer behavior. Journal of Political Economy, 78: 311-329.

Nonaka, I. and H. Takeuchi, 1995. The knowledge-creating company: How Japanese firms create the dynamics of innovation. New York: Oxford University Press.
Rousseau, D.M., S.B. Sitkin, R.S. Burt and C. Camerer, 1998. Not so different after all: A cross-discipline view of trust. Academy of Management Review, 23: 393-404.

Schulze, B. and A. Spiller, 2006. Determinants of trust between buyers and suppliers in agribusiness: Empirical evidence from the German pork sector. In: M. Fritz, U. Rickert and G. Schiefer (Eds.): Trust and risk in business networks, Bonn: ILB-Press, pp. 117-126.

Schulze, B., C. Wocken and A. Spiller, 2006. Relationship quality in agri-food chains: Supplier management in the German pork and dairy sector. Journal on Chain and Network Science, 6: 55-68.

Sherer, S.A., 2003. Critical success factors for manufacturing networks as perceived by network coordinators. Journal of Small Business Management, 41: 325-345.

Sporleder, T.L. and P.D. Goldsmith, 2002. Network embeddedness in the food supply chain and firm strategy on signaling quality. In: J.H. Trienekens and S.W.F. Omta (Eds.): Paradoxes in food chains and networks. Wageningen: Wageningen Academic Publishers, pp. 720-728.

Theuvsen, L., 2003. Rückverfolgbarkeit von Lebensmitteln: Herausforderungen und Lösungsansätze aus organisatorischer Sicht. Berichte über Landwirtschaft, 81: 555-581.

Theuvsen, L., 2004. Transparency in netchains as an organizational phenomenon: Exploring the role of interdependencies. Journal on Chain and Network Science, 4: 125-138.

Theuvsen, L. and T. Hollmann-Hespos, 2007. Investments in tracking and tracing systems: An empirical analysis of German food manufacturers. In: C. Parker et al. (Eds.): Environmental and rural sustainability through ICT. Proceedings of EFITA/WCCA Conference 2007, Glasgow, 2-5 July 2007.

Van de Ven, A.H., A.L. Delbecq and R. Koenig, 1976. Determinants of coordination modes within organizations. American Sociological Review, 41: 322-338.

Van Dijk, S.J., G.M. Duysters and A.J.M. Beulens, 2003. Transparency dilemmas in strategic alliances. Working paper, s'Hertogenbosch: KLICT.

Van Weele, A.J., 2002. Purchasing and supply chain management: Analysis, planning and practice. $3^{\text {rd }}$ edition. London: Thomson Learning.

Williamson, O.E., 1985. The economic institutions of capitalism: Firms, markets, relational contracting. New York and London: Free Press.

Winterstein, H., 1996. Mitarbeiterinformation - Informationsmaßnahmen und erlebte Transparenz in Organisationen. Munich and Mering: Hampp.

Yao, B. and S. McEvily, 2001. Information flow and knowledge creation: The roles of structural embeddedness and knowledge embeddedness in alliance networks. Working paper, University of Pittsburgh. 